\title{
Rutting Resistance Evaluation of Structural Combinations of Asphalt Pavement Subjected to Heavy Duty
}

\author{
Zejiao Dong ${ }^{1, a}$, Xiangbing Gong ${ }^{2, b}$, Guiqing Xiao ${ }^{3, c}$, Teng Long ${ }^{4, d}$ \\ ${ }^{1}$ School of Transportation Science \& Engineering, Harbin Institute of Technology, Harbin 150090, China \\ ${ }^{2}$ School of Transportation Science \& Engineering, Harbin Institute of Technology, Harbin 150090, China \\ ${ }^{3}$ School of Transportation Science \& Engineering, Harbin Institute of Technology, Harbin 150090, China \\ ${ }^{4}$ School of Transportation Science \& Engineering, Harbin Institute of Technology, Harbin 150090, China \\ ahitdzj@hit.edu.cn, bongxiangbing@126.com, cwuxingxgq@sina.com, 'It328166958@163.com
}

\section{Keywords: Asphalt pavement; rutting resistance; structural combination; heavy duty}

\begin{abstract}
Rut, referred to as a common damage of asphalt pavement, is still a knotty problem to pavement researchers. Many reasons could cause rut, among which heavy duty, improper pavement structural combination design are two principal factors. As a result, three pavement structures and seven types of asphalt mixtures were used to evaluate the rutting resistance performance of different structural combinations. At first, through Marshall design method, the properties of asphalt mixtures were obtained such as gradation, asphalt content and so on. Based on the comparison of gradations and anti-rutting additives, the single layer rut was tested by wheel tracking test. Then, in order to consider the influence of pavement structural design on pavement rut, six types of structure combinations under identical heavy duty condition were designed to perform rutting test. It shows that anti-rutting gradation and anti-rutting additives can improve rutting resistance performance of single layer. Also, a proper structural design could provide a better bearing capacity of wheel load even for heavy duty. It is better to integrate the anti-rutting gradation and anti-rutting additives into structural design. In this paper the results provide some new insight into the relationship between rutting resistance and mixture gradation, anti-rutting additives, heavy duty and structural combination. The consideration of these factors will give a better pavement design.
\end{abstract}

\section{Introduction}

In recent years, as the axis load and tire press increase rapidly in most parts of China, as a consequence, rut becomes a common and difficult damage of asphalt pavement, also makes it hard to determine the index of pavement rehabilitation [1]. When rut depth grows to a certain value, it will be potential risk for drivers even meet a rainy day, because surface irregularities of road cross section easily results in vehicle drift. There are so many factors influence rut such as gradation, asphalt types, asphalt content, aggregate and climate, but even if these factors were known very well, it also has difficulties in finding the effective and economic control methods to reduce and avoid rut, so that many relative researches were in aims at some realm of pavement rut. As we all know that asphalt mixtures exhibit viscoelastic characteristic, whose property is relative with the rutting mechanism $[2,3]$, the mechanism of pavement rut is always deemed that the shear stress in the road is bigger than shear strength of asphalt mixtures, especially in long and steep climbing sections of asphalt pavement [4], other researchers search the mechanism to reduce rut by geotextile [5]. Gradation is significant to asphalt mixtures, because of its direct relationship with various properties of mixtures; in addition, the increase of nominal maximum aggregate size (NMAZ) always results in improvement of rutting resistance [6]. Some kinds of additives can modify qualities of asphalt and the aggregate-asphalt interface then generate a strong mix in order to reduce rut [7]. Numerical analysis and pavement structural design are also used to determine what main reason of pavement rut is $[8,9]$.

To establish relevant between rut and gradation, anti-rutting additives, heavy duty, structural design, single layer and structure combination track board were applied into wheel tracking test of heavy tire press $(1.1 \mathrm{MPa})$, analyzed data of different experimental groups then come to a conclusion. 


\section{Marshall design method}

This paper employed seven types of asphalt mixtures according to typical ones used in highway: KAC-16, KAC-20, ATB-25, KAC-25, AC-16, AC-20, AC-25, where $\mathrm{K}$ is mean anti-rutting gradation, shown in Tab.1. The different NMAZ and gradation were for the sake of considering the gradation's impact on pavement rut. Obviously, anti-rutting gradation's limitation is narrower than a normal one, Fig. 1 shows that the aggregates' pass rate of KAC-20 is smaller than AC-20 except $9.5 \mathrm{~mm}$ sieve, anti-rutting gradation is coarser than the normal one.

Tab.1 Seven types of asphalt mix gradation

\begin{tabular}{|c|c|c|c|c|c|c|c|c|c|c|c|c|c|}
\hline $\begin{array}{c}\text { Sieve } \\
\text { size } \\
{[\mathrm{mm}]}\end{array}$ & 31.5 & 26.5 & 19 & 16 & 13.2 & 9.5 & 4.75 & 2.36 & 1.18 & 0.6 & 0.3 & 0.15 & 0.075 \\
\hline ATB-25 & 100 & 100 & 64.8 & 54.1 & 46.6 & 39.8 & 32 & 21.1 & 16 & 11.4 & 8.1 & 6.9 & 5.9 \\
\hline KAC-25 & 100 & 100 & 82.3 & 75.2 & 66.4 & 57.3 & 34.7 & 23.5 & 16 & 11.8 & 7.6 & 6.7 & 5.5 \\
\hline KAC-20 & - & 100 & 91.7 & 85.7 & 73.5 & 61.4 & 37.5 & 23.4 & 15.6 & 10.8 & 7.8 & 6.8 & 5.9 \\
\hline KAC-16 & - & - & 99.7 & 95.4 & 82.9 & 70.5 & 43.9 & 27.2 & 17.2 & 11.4 & 8.1 & 6.9 & 5.9 \\
\hline AC-25 & 100 & 100 & 88.7 & 78 & 69.6 & 54.2 & 37.5 & 28.5 & 21.4 & 15.7 & 11.4 & 7.2 & 5.7 \\
\hline AC-20 & - & 100 & 93.9 & 87.4 & 78.7 & 59.5 & 39.9 & 28.6 & 21.4 & 15.7 & 11.4 & 7.2 & 5.7 \\
\hline AC-16 & - & - & 100 & 94.1 & 86.7 & 67.2 & 40.9 & 29.3 & 22.3 & 16.4 & 11.7 & 9.5 & 6.8 \\
\hline
\end{tabular}

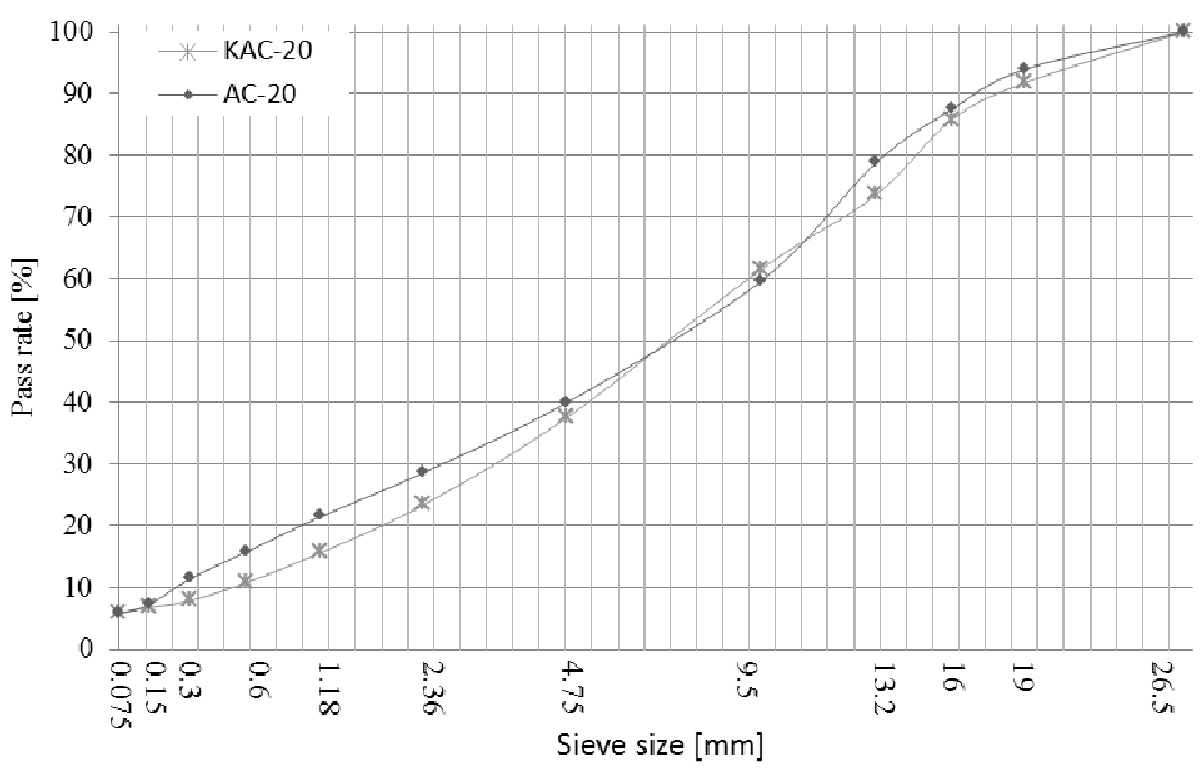

Fig.1 KAC-20 and AC-20 gradation curves

After gradations were determined, Marshall design method was applied to calculate the optimum asphalt content of seven mixtures, then obtained some volume indexes shown in Tab 2. All the data met requirements of Enforceable Handbook of Technical Specifications for Construction of Highway Asphalt Pavements.

Tab.2 Data of Marshall design method

\begin{tabular}{|c|c|c|c|c|c|c|}
\hline Types & OAC [\%] & $\gamma_{\mathrm{b}}\left[\mathrm{g} / \mathrm{cm}^{3}\right]$ & $\mathrm{VV}[\%]$ & $\mathrm{VFA}[\%]$ & $\mathrm{MS}[\mathrm{KN}]$ & $\mathrm{FL}[\mathrm{mm}]$ \\
\hline ATB-25 & 3.8 & 2.537 & 4.0 & 60 & 11.3 & 2.32 \\
\hline KAC-25 & 4.1 & 2.400 & 4.5 & 62.9 & 10.5 & 2.90 \\
\hline KAC-20 & 4.9 & 2.500 & 4.8 & 67.0 & 12.1 & 3.70 \\
\hline KAC-16 & 5.1 & 2.467 & 3.6 & 73.8 & 11.8 & 2.90 \\
\hline AC-25 & 4.2 & 2.500 & 4.5 & 68.3 & 8.9 & 2.93 \\
\hline AC-20 & 4.7 & 2.495 & 4.4 & 69.0 & 15.5 & 3.70 \\
\hline AC-16 & 5.4 & 2.459 & 4.5 & 71.2 & 10.6 & 3.94 \\
\hline
\end{tabular}




\section{Single layer wheel tracking test}

Based on data of the first section, gradation and asphalt content were applied into single layer wheel tracking test to estimate and check the property of anti-rutting resistance. According to Standard Test Methods of Bitumen and Bituminous Mixtures for Highway Engineering, wheel rolling equipment was used to shape experimental boards $(300 \mathrm{~mm} \times 300 \mathrm{~mm} \times 50 \mathrm{~mm})$, wheel track testing was in $60^{\circ} \mathrm{C}$ and remained 60 minutes at least until the curve reached stable. At last, the $D S$ (Dynamical Stability) could be worked out by formula 1

$D S=\frac{\left(t_{2}-t_{1}\right) \times N}{d_{2}-d_{1}} \times C_{1} \times C_{2}$

Where $t_{1}$ and $t_{2}$ are the 45 minute and 60 minute from test began, $d_{1}$ and $d_{2}$ are corresponding deformation of $t_{1}$ and $t_{2}, C_{1}$ is correction factor of wheel tracking test equipment, in this test it is 1.5, $C_{2}$ is specimen coefficient depending on the size of tracking boards, it is 1.0 in this test, $N$ is velocity of wheel tracking tire moving there and back, it is 42 round per minute.

In this section, took gradation and anti-rutting additives into consideration subjected to single layer test, but used normal tire press $(0.7 \mathrm{MPa})$. Aimed at finding how do these two factors effect rut, the results of these differently compared groups shown as follow.

Gradation. From Fig.2, it shows that anti-rutting gradation has a positive influence on improving the capacity to resist vehicle loads. The $D S$ of KAC-20 increases by $17.4 \%$ comparing to AC-20, and the result of KAC-16 increases by $28.5 \%$ comparing to AC-16, while to KAC-25, it decreases by $3.4 \%$, because when NMAZ reaches $26.5 \mathrm{~mm}$, the anti-rutting gradation seems similar with normal one when keeping a qualified VV. If just only increase the difference between two types of gradation, the anti-rutting one will be difficult to meet the regulation requirement such as a proper VV. But KAC-20 and KAC-16 do not have these problems, a wider selection in gradation than KAC-25. The maximum $D S$ is exhibited in $19.5 \mathrm{~mm}$ NMAZ either anti-rutting or normal gradation.

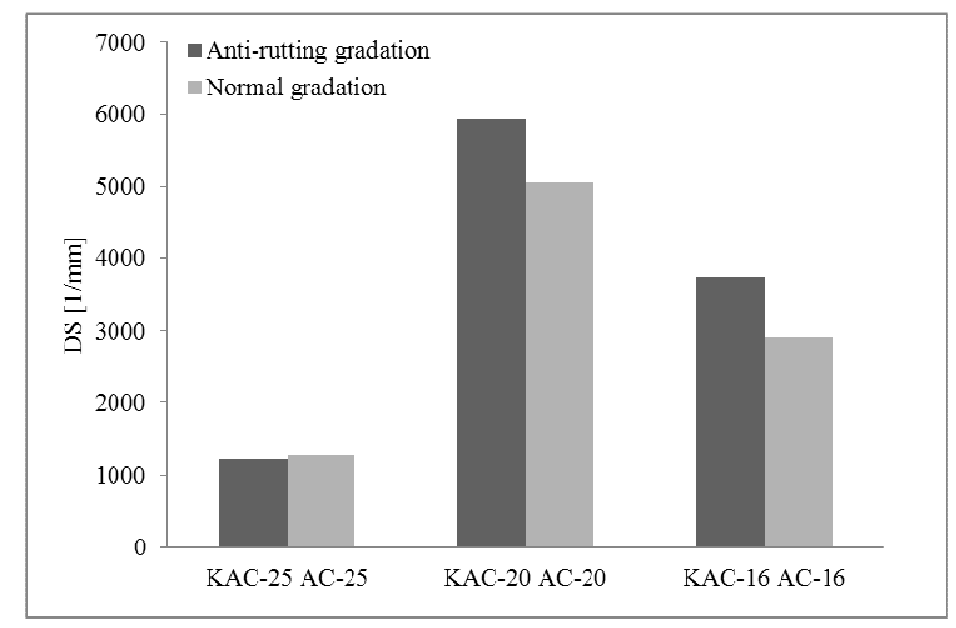

Fig.2 $D S$ of different gradations

Anti-rutting additives. As a kind of modifiers, anti-rutting additive is playing a important role in modifying asphalt, it can improve cohesivness of asphalt and aggregate, also strenghen interface peeling resistance betweeen asphalt and aggregate. So this additive not only enhances anti-rutting capacity also improves low temperature cracking resistance. In this section, KTL additive was chosen because of its wide use in China and it has a good effectness, known as a kind of product of Beijing Tian Cheng KenTeiLai Technology Co., Ltd. Following recomment, dosage of admixture is $0.3 \%$, and all gradations were chosen as anti-rutting gradation type, wheel tracking test results are illustrated in Fig.3, where + is added KTL anti-rutting additives into gradation.

It is obvious that KTL additive improves rut resistance. Comparing to KAC-16 and KAC-20, the KTL gradations' $D S$ increase by $88.4 \%$ and $78.6 \%$, which are siginificantly effectiver than anti-rutting gradtion. Then after combination of KTL additive and anti-gradation, it strenghened cappacity of rutting resistance, in addition, KTL additive is more cheaper than others. 


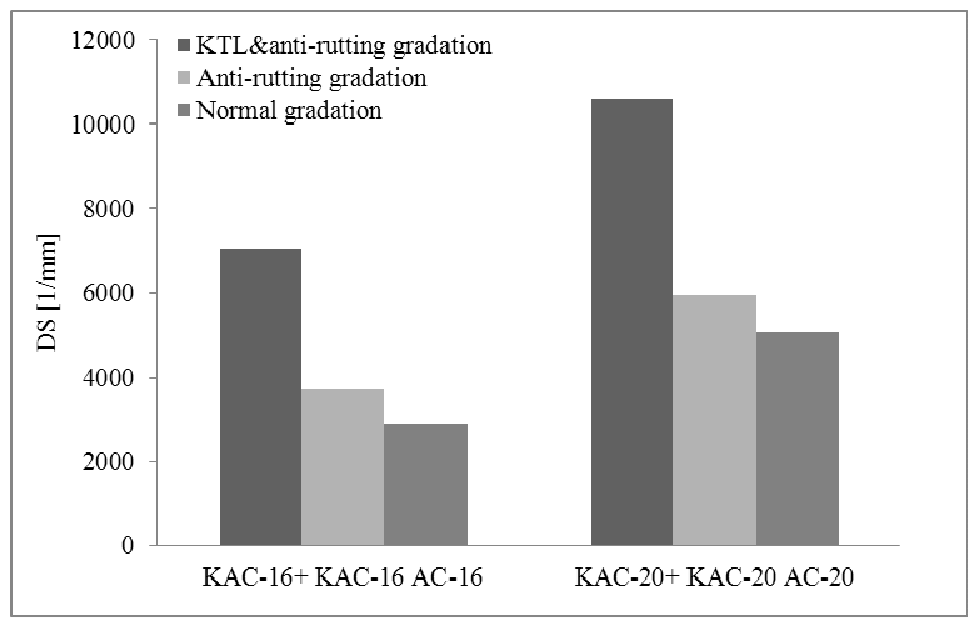

Fig.3 DS of different gradations and KTL additive

\section{Combined structure boards wheel tracking test}

Besides gradations and anti-rutting additives, pavement rut is always sensitive to pavement structural design, it could be proved that single layer wheel tracking test does not comfirm real high temperature performance of highways. In this section, two layer combined structure boards chosen among three pavement strucures of real projects were applied to simulate the real pavement structures, the boards and pavement structures are shown in Fig.4 and Tab.3.

Tab.3 Three pavement structures

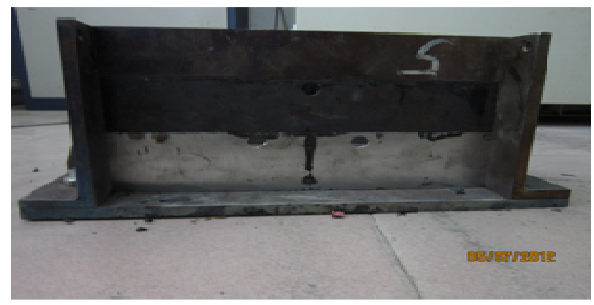

Fig.4 Two layer combined structure boards \begin{tabular}{l|l|l} 
Structure 1 & Structure 2 & Strucure 3 \\
\hline
\end{tabular}

\begin{tabular}{|c|c|c|c|}
\hline Layer & Structure 1 & Structure 2 & Strucure 3 \\
\hline Upper layer & $5 \mathrm{~cm}$ SBS AC-16 & $\begin{array}{c}5 \mathrm{~cm} \text { SBS+KTL } \\
\text { KAC-16 }\end{array}$ & $\begin{array}{c}5 \mathrm{~cm} \text { SBS+KTL } \\
\text { KAC-16 }\end{array}$ \\
\hline Middle layer & $6 \mathrm{~cm}$ SBS AC-20 & $\begin{array}{c}6 \mathrm{~cm} \mathrm{SBS+KTL} \\
\text { KAC-20 }\end{array}$ & $\begin{array}{c}6 \mathrm{~cm} \text { SBS+KTL } \\
\text { KAC-20 }\end{array}$ \\
\hline Bottom layer & $7 \mathrm{~cm} \mathrm{AC-25}$ & $7 \mathrm{~cm} \mathrm{KAC-25}$ & $7 \mathrm{~cm} \mathrm{ATB-25}$ \\
\hline
\end{tabular}

Heavy duty. Based on heavy duty investigation, the tire press of wheel track is 1.1MPa.

Combined structure design. Classification of combined structure is distinguished by different layer and structure combination, so that experimental groups' serial number is defined as $\mathrm{H}-\mathrm{K}$, when $\mathrm{H}$ is 1 , which means that boards is combined by upper and middle layer, $\mathrm{H}$ is 2 means that middle and bottom layer, $\mathrm{K}$ is 1 means that structure 1 , the rest can be done in the same manner. Then the wheel tracking test of heavy duty and combined structure were conducted, the results are shown in Fig.5.

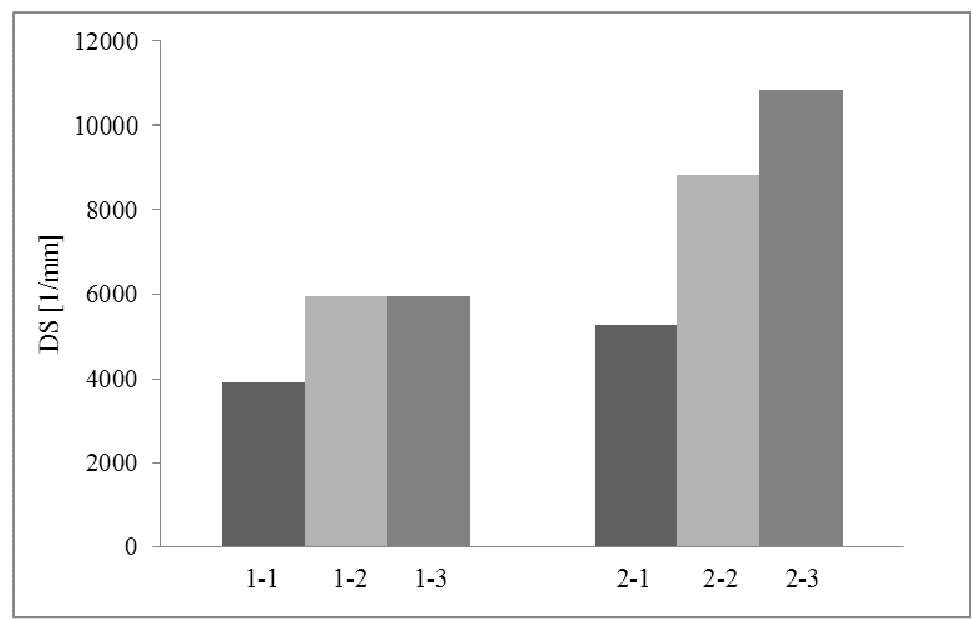

Fig.5 DS of different groups 
Analyzed data of groups, comparing to single layer test results, combined structure boards could be more balanced, because the combination intergrates the difference bettween two kinds of single layers, such as 1-1, DS of AC-16 and AC-20 is 2907 and 5054, while the combined one is 3917, this phenomenon is same to other groups, which shows that combined strucure boards are similar to real pavement structures. For group 1 and group 2, the KTL additive and anti-rutting gradation are important to improve strutural rutting resistance, a substaintial increase shows in figure. What more, the combination of middle and bottom layers exhibilts a better anti-rutting capacity than one of upper and middle layers, as a result, these two layers play a significant role in bearing heavu duty. For group 2 , the difference of 2-2 and 2-3 is diverse bottom layer, 2-2 is KAC-25 and 2-3 is ATB-25, the result of 2-3 increases by $22.7 \%$, it is remarkable that a flexiabler layer such as ATB- 25 can provide a more reseaonable strucure combination for rutting resistance, because flexiable layer can dissipate more vehicles moving energy.

\section{Summary and conclusion}

The major objective of the study presented in this paper is to find the relationship between rut and gradation, anti-rutting additives, structural design. The effort has provide different groups and experimental boards to evaluate the rut resistance of them, then got some conclusions as follow.

1. Anti-rutting gradation and anti-rutting additives can improve the capacity to avoid rut, however a coarse gradation has some limitation, and it is a kind of physical method. What more, additive has a advantage in enhancing properties of asphalt mixtures, its effectness is better than anti-rutting gradation.

2. Test results of single layer board based on diverse mixture are extremely various, combined strucure boards are similar to real pavement structures and $D S$ of combined structure boards seem to be more balanced..

3. Combination of middle and bottom layer shows a stronger resistance than upper and middle layer combination, these two layers play a significant role in bearing heavu duty. What more, on the basis of comparation between 2-2 and 2-3 experimental groups, the result of 2-3 increases by $22.7 \%$. A flexiabler layer such as ATB-25 might provide a properer structure combination for rutting resistance, because flexiable layer can dissipate more vehicles moving energy.

\section{References}

[1] Panagiotis Ch. Anastasopoulos, Fred L. Mannering, John E. Haddock, A Random Parameters Seemingly Unrelated Equations Approach to the Post-Rehabilitation Performance of Pavements, Journal of Materials in Civil Engineering (2012).

[2] Ronald Blab, John T. Harvey, Modeling Measured 3D Tire Contact Stresses in a Viscoelastic FE Pavement Model, The International Journal of Geomechanics vol.3 (3) (2002), p:271-290.

[3] Jaeseung Kim, Reynaldo Roque, Thomas Byron, Viscoelastic Analysis of Flexible Pavements and Its Effects on Top-Down Cracking, Journal of Material in Civil Engineering vol.21 (7) (2009), p:324-332.

[4] J. Z. Pei, Y. Chen, M. F. Chang, Mechanism of Rutting Formation in Long and Steep Climbing Sections of Asphalt Pavement, Proceedings of the Ninth International Conference of Chinese Transportation Professionals (2009), p:2179-2197.

[5] Yinghao Miao, Jinxi Zhang, Mechanism of Mitigating Shear-induced Rutting of Asphalt Pavement Using Geotextile, Airfield and Highway Pavement (2008), p:16-27.

[6] LIU Hong-ying, DAI Jing-liang, Effect of different gradations on asphalt mixture resistance to rut, Journal of Chang'an University (Natural Science Edition) vol.24 (5) (2004), p:11-15.(In Chinese) 
[7] Elie Y. Hajj, Peter E. Sebaaly, Thileepan Sathanathan et al, Impact of Anti-strip Additives on Pavement Performance Using M-E Pavement Design Guide, Journal of Materials in Civil Engineering (2012).

[8] Zejiao Dong, Zongjie Sun, Xiangbing Gong et al, Mechanism Analysis of Rutting at Urban Intersections Based on Numerical Simulation under Moving Vehicle Loads, Advanced Materials Research vol.152-153 (2011), p:1192-1198.

[9] ZHANG Dongsheng, XU Xijuan, ZHANG Mingcheng et al, Semi-flexible Base's Material Properties and Pavement Structure Applicability, Proceedings of the Third International Conference on Transportation Engineering (2011), p:2139-2144. 